\title{
Knowledge toward Drugs Resistant Tuberculosis in One of the Highest Burden Drug Resistant Country
}

\author{
Amalia Rizki Ramadhani, ${ }^{1}$ Bony Wiem Lestari, ${ }^{2}$ Hendarsyah Suryadinata ${ }^{3}$ \\ ${ }^{1}$ Faculty of Medicine Universitas Padjadjaran, Indonesia, ${ }^{2}$ Department of Public Health Faculty of \\ Medicine Universitas Padjadjaran, Bandung, Indonesia, ${ }^{3}$ Department of Internal Medicine Faculty \\ of Medicine Universitas Padjadjaran/Dr. Hasan Sadikin General Hospital Bandung, Indonesia
}

\begin{abstract}
Background: Drug resistant tuberculosis (DR-TB) is the biggest threat in TB case control worldwide. West Java Province is one of the three provinces with the most DR-TB burden in Indonesia. Knowledge level in DR-TB patients influences the perception, health search effort, and patient compliance towards DR-TB treatment. This study was aimed to identify the knowledge level about DR-TB in DR-TB patients at Hasan Sadikin General Hospital.

Methods: This cross-sectional, descriptive quantitative study used consecutive sampling. In the study 96 patients were included. Primary data were collected through interview with questionnaire towards DRTB patients at MDR-TB Clinic Hasan Sadikin General Hospital during September-November 2016. The questionnaire contained sociodemographic data and knowledge about DR-TB which consisted of definition, transmission, risk factors, resistance types, symptoms, medication, and prevention of DR-TB. The collected data were analyzed using statistical software for descripitive statistical analysis.

Results: The average age of patients was 38 years (SD \pm 11.7$)$ and mostly ranging from 36-45 years old. Male had a higher distribution compared to female (55.2\%). Analysis results showed $20 \%$ patients had "Adequate" knowledge level, $34.4 \%$ of the patients had "Sufficient" knowledge, and $39.6 \%$ of the patients had "Poor" knowledge about DR-TB.
\end{abstract}

Conclusions: DR-TB patients at MDR-TB Clinic Dr. Hasan Sadikin General Hospital Bandung have "poor" knowledge regarding DR-TB.

Keywords: Drug Resistant TB, knowledge, patients

\section{Introduction}

Drug Resistant Tuberculosis (DR-TB) is a type of tuberculosis (TB) caused by tuberculosiscausing bacteria, Mycobactrerium tuberculosis (Mtb) which have developed resistance to Anti Tuberculosis Drug (ATD). This is the greatest threat in TB management in the whole wide world. Indonesia is one of the six countries with the highestDR-TB burden in the world with 6800 cases of DR-TB in the year 2014 and the number kept increasing by $1.9 \%$ each year. ${ }^{1}$ The increased number of DR-TB cases in Indonesia has caused the government to bear increasing costs to manage and control the DRTB cases. ${ }^{2}$

The DR-TB occurs by two different mechanisms. The first mechanism is a patient infected by Mtb is already resistant to drugs. The second mechanism is a patient has an acquired resistance due to inadequate treatment. This cause the previously susceptible Mtb to develop genetic mutations which makes it resistant to ATDs. Inadequate treatments include inadequate drugs dosage, inadequate absorption rate of drugs through the gastrointestinal system, inadequate quality of ATDs, as well as lack of patients' compliance in continuously consuming ATDs. ${ }^{3-5}$

The level of knowledge will greatly affect the behavior, particularly the health behavior. ${ }^{6}$ The knowledge level of DR-TB patients will affect their perception regarding the disease, their efforts in looking for treatment, and their compliance towards DR-TB treatment regiments. The knowledge level will then have

Correspondence: Amalia Rizki Ramadhani, Faculty of Medicine, Universitas Padjadjaran. Jalan Raya Bandung-Sumedang Km. 21, Sumedang, Indonesia Email: amaliarizki202@gmail.com 
an important role to minimalize the spread of disease, as part of the efforts to decrease the rate of morbidity and mortality incurred by DR-TB. ${ }^{7-9}$ West Java Province is one of the three provinces with the greatest burden of DR-TB in Indonesia, does not have sufficient data regarding the knowledge level of patients diagnosed with DR-TB up until presently ${ }^{10}$ Therefore, this study was aimed to identify the knowledge level regarding DR-TB in patients diagnosed with DR-TB at Dr. Hasan Sadikin General Hospital Bandung.

\section{Methods}

This study was a cross-sectional, quantitative descriptive study. The evaluated data were primary data collected through selfadministered questionnaires at MDR-TB Clinic Hasan Sadikin General Hospital. This study was held in September-November 2016. The sample population were patients diagnosed with DR-TB who at the time of the study underwent an intensive period of DRTB treatment during September-November 2016. The sampling technique used was consecutive sampling. The inclusion criteria in this study were patients aged $\geq 18$ years and were still undergoing intensive period of DR-TB treatment. Patients diagnosed with DR-TB who were hospitalized and had speech impaired were not included in the study. The total number of patients who were undergoing intensive treatment during the period September-November 2016 at MDR-TB Clinic Hasan Sadikin General Hospital were 105 patients, however the total number of patients included in this study were 96 patients.

The instrument employed in this study was a modified questionnaire which derived from questionnaires used in previous studies. . $^{8,1-13}$ The questionnaire included questions regarding demographic data such as patients' identity, number of previous TB treatment, and duration of DR-TB treatment at the time of the study, and 20 items on knowledge consisting of true or false questions about definition, etiology, method of transmission, type of resistance, symptoms, treatment, and prevention of DR-TB. ${ }^{8,11-13}$ The questionnaire used in this study was tested for validity and reliability on 70 patients from May-August 2015. All questions were qualified as valid with Alpha Cronbach score of 0.78 .

The collected data were processed and analyzed using statistical software for descriptive statistical analysis and presented in the forms of narratives and figures. Numerical variables were presented as mean or median as well as standard deviations (SD) and range. Categorical variables were presented as distribution of frequency (n) and percentage (\%). Normality test of the data of patients' knowledge level showed that the data were not normally distributed, thus, the grouping of patients' knowledge level was based on the value of interquartile range. The patients' knowledge level were classified into three categories, namely "adequate" if the score was $\geq 15$, "sufficient" if the score was in the range

Table 1 Demographic characteristics of DRTB Patients on Age, Sex, Patient's Location, Marital Status, and Occupation

\begin{tabular}{lc}
\hline \multicolumn{1}{c}{ Patient Characteristics } & $\mathbf{n}(\%)$ \\
\hline Age (years old) & $12(12.5)$ \\
$18-25$ & $25(26)$ \\
$26-35$ & $39(40.6)$ \\
$36-45$ & $11(11.5)$ \\
$46-55$ & $7(7.3)$ \\
$56-65$ & $2(2.1)$ \\
$>60$ & \\
Sex & $53(55.2)$ \\
Male & $43(44.8)$ \\
Female & \\
Patient's location & $27(28.1)$ \\
Bandung city & $69(71.9)$ \\
Outside of Bandung city & \\
Marital status & $19(19.8)$ \\
Unmarried & $72(75)$ \\
Married & $3(3.1)$ \\
Divorced with a living spouse & $2(2.1)$ \\
Divorced with a passed-away spouse & $19(19.6)$ \\
Occupation & $25(26)$ \\
Civil servant & \\
Private companies employee & \\
Self-employed & \\
Students & \\
\hline Housewives & \\
\hline
\end{tabular}


Table 2 Demographic Characteristics of DR-TB patients on Monthly Income, Educational Status, Referral Source, History of Previous TB Treatment, and Duration of DR-TB Treatment

\begin{tabular}{lc}
\multicolumn{1}{c}{ Patient Characteristic } & $\mathbf{n}(\mathbf{\%})$ \\
\hline Monthly income (Rp.) & $54(56.3)$ \\
$<1.500 .000$ & $24(25)$ \\
$1.500 .000-2.500 .000$ & $2(2.1)$ \\
$2.500 .000-3.500 .000$ & $16(16.7)$ \\
$>3.500 .000$ & \\
Educational status & $0(0)$ \\
$\quad$ No formal education & $0(0)$ \\
Elementary school (not graduated) & $9(9.4)$ \\
Graduated from elementary school & $25(26)$ \\
Graduated from junior high school & $47(49)$ \\
Graduated from senior high school & $14(14.6)$ \\
Diploma/Bachelor degree & $1(1)$ \\
Magister & \\
Referral source & $51(53.1)$ \\
Public health centers & $31(32.3)$ \\
Public hospitals & $12(12.5)$ \\
Private hospitals & $1(1)$ \\
Private clinics & $1(1)$ \\
Self-practicing general practitioners & $2(0-5)$ \\
History of previous TB treatment (times)* & \\
(median/minimum-maximum) & $3(0-18)$ \\
Duration of DR-TB treatment (month)** & \\
(median/minimum-maximum) &
\end{tabular}

from $12-14$, and "poor" if the patient's score was $<12$.

This study obtained permission from the Health Research Ethical Committee of Faculty of Medicine, Universitas Padjadjaran Num. 505/UN.6.C1.3.2/KEPK/PN/2016 and the Education and Research Division of Dr. Hasan Sadikin General Hospital Num. LB.02.01/ C02/8952/VII/2016.

\section{Results}

This study showed that male patients had a higher distribution compared to female patients and mean age of DR-TB patients were 38 years $(S D \pm 11.7)$. Most patients lived outside the city of Bandung (71.9\%) and the majority of patients were temporary worker (labor) with the percentage $28.1 \%$ (Table 1). As many as 51 patients $(53.1 \%)$ were referred from Public Health Centers (Pusat Kesehatan Masyarakat, Puskesmas) (Table 2).

The majority of DR-TB patients had "poor" knowledge regarding DR-TB (39.6\%) and only a few patients (26\%) had "adequate" knowledge regarding DR-TB (Table 3).

As many as 21 people out of 96 patients (21.9\%) answered that DR-TB was an

Table 3 Knowledge level of DR-TB patients

\begin{tabular}{lc}
\hline \multicolumn{1}{c}{ Knowledge level } & n (\%) \\
\hline Adequate & $25(26)$ \\
Sufficient & $33(34.4)$ \\
Poor & $38(39.6)$ \\
\hline
\end{tabular}


infectious disease caused by bacteria, and 63 people $(65.6 \%)$ answered correctly that DR-TB was not a genetically inherited disease. Only 16 people $(16.7 \%)$ were aware that DR-TB was caused by the bacteria named Mycobacterium tuberculosis (Table 4).

Furthermore, knowledge regarding transmission of DR-TB was quite sufficient. However, there was still a false understanding regarding the transmission of DR-TB. As many as 50 people $(52.1 \%)$ stated that DR-TB was able to be transmitted through blood products. and 56 people $(58.3 \%)$ stated that DR-TB could be transmitted through sharing food and drinks with another patient (Table 4).

Moreover, knowledge regarding risk factors of DR-TB was categorized as adequate, as more than $50 \%$ patients were able to answer correctly that people with close contact to patients diagnosed with DR-TB (88.5\%), patients diagnosed with HIV (50\%), and patients with history of previous TB treatment

Table 3 Knowledge Level of DR-TB Patients

\begin{tabular}{|c|c|c|}
\hline Variable & Correct $(n, \%)$ & Wrong (n, \%) \\
\hline \multicolumn{3}{|l|}{ Definition } \\
\hline Infectious disease caused by bacteria & $21(21.9)$ & $75(78.1)$ \\
\hline Not genetically inherited & $66(66.6)$ & $33(34.4)$ \\
\hline \multicolumn{3}{|l|}{ Etiology } \\
\hline Caused by Mycobacterium tuberculosis & $16(16.7)$ & $80(83.3)$ \\
\hline \multicolumn{3}{|l|}{ Transmission } \\
\hline Mucus droplets during sneezing & $94(97.9)$ & $2(2.1)$ \\
\hline Blood products & $46(47.9)$ & $50(52.1)$ \\
\hline Physical contact (shaking hands) & $83(86.5)$ & $13(13.5)$ \\
\hline Food borne & $40(41.7)$ & $56(58.3)$ \\
\hline \multicolumn{3}{|l|}{ Risk factors } \\
\hline Household contact & $85(88.5)$ & $11(11.5)$ \\
\hline HIV* & $48(50)$ & $48(50)$ \\
\hline History of previous TB treatment** & $88(91.7)$ & $8(8.3)$ \\
\hline \multicolumn{3}{|l|}{ Resistance type } \\
\hline Primary resistance & $88(91.7)$ & $8(8.3)$ \\
\hline Acquired resistance & $94(97.9)$ & $2(2.1)$ \\
\hline \multicolumn{3}{|l|}{ Symptoms } \\
\hline Sudden loss of body weight & $92(95.8)$ & $4(4.2)$ \\
\hline \multicolumn{3}{|l|}{ Diagnostic test } \\
\hline Rapid laboratory test (Gene Xpert) & $68(70.8)$ & $28(29.2)$ \\
\hline \multicolumn{3}{|l|}{ Treatment } \\
\hline Place of treatment and follow up & $47(49)$ & $49(51)$ \\
\hline Total duration of DR-TB treatment $†$ & $30(31.3)$ & $66(69.7)$ \\
\hline Length of intensive phase & $76(75)$ & $24(25)$ \\
\hline Name of drugs used in DR-TB treatment $\neq$ & $28(29.2)$ & $68(70.8)$ \\
\hline \multicolumn{3}{|l|}{ Prevention } \\
\hline Sputum disposal & $46(47.9)$ & $50(52.1)$ \\
\hline Not sharing room with non-DR-TB patients§ & $81(84.4)$ & $15(15.6)$ \\
\hline
\end{tabular}

Note: ${ }^{*}$ Human Immunodeficiency Virus,${ }^{* *}$ Tuberculosis, $\uparrow, \ddagger, \S$ Drug resistant Tuberculosis 
(91.7\%) were at high risk for contracting DRTB. Patients also had adequate knowledge regarding the type of resistance, symptoms of DR-TB, and rapid test to diagnosed DR-TB (Table 4).

On questions regarding the treatment for DR-TB, only 47 people (49\%) stated that the main treatment for DR-TB could only be conducted at certain hospitals approved by the government and then referred back to health facilities which were more accessible for patients, such as Public Health Centers or District General Hospitals. Patients were also aware that the administration of antituberculosis drugs through injections was carried outd during the intensive phase of DRTB treatment $(75 \%)$. On questions regarding the total length of duration for DR-TB treatment only 30 people $(31.3 \%)$ stated that the total length for DR-TB treatment was >18 months. As many as 68 patients $(70.8 \%)$ were not aware of the names of anti-tuberculosis drugs provided to them. Patients were aware that DR-TB could be prevented by removing their phlegm in places exposed by sun $(47.9 \%)$ and rooms for DR-TB patients should be separated from other patients $(84.4 \%)$.

\section{Discussions}

This study showed that the distribution of patients diagnosed with DR-TB was higher in males compared to females. This is consistent with the studies by Myet et al. ${ }^{9}$ in Myanmar, Li et al. ${ }^{11}$ in China, and Mulu et al. ${ }^{14}$ at Amhara, Ethiopia, which stated there are more men afflicted with DR-TB than women. Different results were obtained from the study by Ullah et al. ${ }^{15}$ in Pakistan, and Liu et al. $^{16}$ in China which showed that there are more female patients than male patients, even though there are no clear known relationships between sex and risks of contracting DR-TB yet. From the age factor, it is known that people of productive age are more likely to contract DR-TB than the elderly ( $\geq 65$ years old), which is similar to the results of the study by Nair et al. ${ }^{17}$ in India. This study found that the mean age of DR-TB patients were 38 years, mostly ranging from 36 to 45 years old, even though there was no fixed limits for the range of age that was more susceptible to DR-TB due to various cut off points for age in each study. ${ }^{15}$ As many as 72 patients $(75 \%)$ were married, consistent with the results of the studies by Myet et al. ${ }^{9}$ in Myanmar and Li et al. ${ }^{11}$ in China. As much as 27 patients $(28.1 \%)$ are temporary workers or labor, similar to the result of the study by Mulu et al..$^{14}$ at Amhara, Ethiopia.

This study discovered that most patients had previous TB treatments. Previous history of TB treatment is one of the risk factors for DR-TB, as shown in the study by Elmi et al. ${ }^{18}$ in Malaysia and the study by Liu et al. ${ }^{16}$ in China which reported that the history of a previous TB treatment is a risk factor for DR-TB which may also indicate patients' lack of compliance during treatment. Another study by Daniel et al. ${ }^{19}$ in Nigeria also mentioned that patients with history of a previous TB treatment are more prone to develop DR-TB.

This study showed that most of the patients had poor knowledge regarding DRTB. Different results were found in the study by Myet et al. ${ }^{9}$ in Myanmar, and Maharaj et al. ${ }^{20}$ in South Africa, which reported that patients have adequate knowledge regarding DR-TB. Patients enrolled in this study are mostly still unaware of the exact etiology of DR-TB, either the type or the name of the microorganism which cause DR-TB, risk factor of DR-TB, the transmission of DR-TB and the name of the drugs they received during the treatment period for DR-TB. Maharaj et al. ${ }^{20}$ suggested that by knowing the name of the drugs they received, patients would be more aware of the side effects of the drugs so that they would be more compliant towards the treatment regiments.

The limitation of this study was the sample population only consisted of patients who underwent treatment at Hasan Sadikin General Hospital Bandung, while there were also patients diagnosed with DR-TB who underwent treatment at The Center for Lung Health Community (Balai Besar Kesehatan Paru Masyarakat, BBKPM) Cibadak, and Rotinsulu Lung Hospital Bandung. This study also did not discover the association between DR-TB patients' sociodemographic characteristics and knowledge level regarding DR-TB.

In conclusion, DR-TB patients at Dr. Hasan Sadikin General Hospital Bandung have "poor" knowledge about DR-TB. Therefore, it is important for the government and health professionals to increase promotional and educational efforts, such as creatingeducational media (video, pamphlet, brochures) regarding DR-TB for the community, especially for patients.

\section{References}

1. World Health Organization. Global tuberculosis report 2013. Geneva: WHO 
Press; 2015.

2. Van den Hof S, Collins D, Hafidz F, Beyene D, Tursynbayeva A, Tiemersma E, et al. The socioeconomic impact of multidrug resistant tuberculosis on patients: results from Ethiopia, Indonesia and Kazakhstan. BMC Infect Dis. BMC Infectious Diseases; 2016;16(1):470-84.

3. Nugroho RA. Studi kualitatif faktor yang melatarbelakangi drop out pengobatan tuberkulosis paru. J Kesehat Masy. 2011;7(1):83-90.

4. Oblast A, Smith SE, Ershova J, Vlasova N, Nikishova E, Tarasova I, et al. Risk factors for acquisition of drug resistance during multidrug-resistant tuberculosis. Emerg Infect Dis. 2015;21(6):1002-11.

5. Kementerian Kesehatan RI. Petunjuk teknis manajemen terpadu pengendalian tuberkulosis resistan obat. Jakarta: Kemenkes RI; 2013.

6. Manika D, Golden LL. Advances in prior knowledge conceptualizations: investigating the impact on health behavior. In: Plangger K, editor. Thriving in a New World Economy. 4th ed. London: Springer; 2015. p. 319-29.

7. Bam K, Bhatt LP, Thapa R, Dossajee HK, Angdembe MR. Illness perception of tuberculosis (TB) and health seeking practice among urban slum residents of Bangladesh: a qualitative study. BMC Res Notes. 2014;7(1):572-8.

8. Fox GJ, Loan LP, Nhung NV, Loi NT, Sy DN, Britton WJ, et al. Barriers to adherence with tuberculosis contact investigation in six provinces of Vietnam: a nested case-control study. BMC Infect Dis. 2015;15(1):103-11.

9. MyetH,MaungW,SawS, OoWM. Knowledge and practice on MDR-TB disease among MDR-TB patients attending Aung San MDRTB Clinic (Yangon). Myanmar Heal Sci Res J. 2015;27(1):77-82.

10. Kementerian Kesehatan RI. Laporan situasi perkembangan TB MDR di Indonesia Triwulan II Tahun 2015. Jakarta: Kemenkes RI; 2015.

11. Li Y, Ehiri J, Oren E, Hu D, Luo X, Liu Y, et al. Are we doing enough to stem the tide of acquired MDR-TB in countries with high TB burden? Results of a mixed method study in Chongqing, China. PLoS One. 2014;9(2):1-12.

12. Tang S, Tan S, Yao L, Li F, Li L, Guo X, et al. Risk factors for poor treatment outcomes in patients with MDR-TB and XDR-TB in China: retrospective multi-center investigation. PLoS One. 2013;8(12):1-8

13. Tupasi TE, Marie A, Garfin CG, Kurbatova E V, Mangan JM, Orillaza-chi $R$, et al. Factors associated with loss to follow-up during treatment for multidrug-resistant tuberculosis, the Philippines, 2012-2014. Emerg Infect Dis. 2016;22(3):491-502.

14. Mulu W, Mekonnen D, Yimer M, Admassu A, Abera B. Risk factors for multidrug resistant tuberculosis patients in Amhara National Regional State. Afr Health Sci. 2015;15(2):368-77.

15. Ullah I, Javaid A, Tahir Z, Ullah O, Shah AA, Hasan F, et al. Pattern of drug resistance and risk factors associated with development of drug resistant Mycobacterium tuberculosis in Pakistan. PLoS One. 2016;11(1):1-7

16. Liu Q, Zhu L, Shao Y, Song H, Li G, Zhou $\mathrm{Y}$, et al. Rates and risk factors for drug resistance tuberculosis in Northeastern China. BioMed Cent Ltd. 2013;13(1171):17.

17. Nair SA, Raizada N, Sachdeva KS, Denkinger C, Schumacher S, Dewan P, et al. Factors associated with tuberculosis and rifampicin-resistant tuberculosis among symptomatic patients in India: a retrospective analysis. PLoS One. 2016;11(2):1-9.

18. Elmi OS, Hasan H, Abdullah S, Mat Jeab MZ, Bin Alwi Z, Naing NN. Multidrug-resistant tuberculosis and risk factors associated with its development: a retrospective study. J Infect Dev Ctries. 2015;9(10):1076-85.

19. Daniel O, Osman E. Prevalence and risk factors associated with drug resistant TB in South West, Nigeria. Asian Pac J Trop Med. 2011;4(2):148-51.

20. Maharaj J, Ross A, Maharaj NR, Campbell L. Multidrug-resistant tuberculosis in KwaZulu-Natal, South Africa: an overview of patients' reported knowledge and attitudes. African J Prim Heal care Fam Med. 2016;8(1):1-6. 